\title{
Absorption and tolerability of taste-masked hydrocortisone granules in neonates, infants and children under 6 years of age with adrenal insufficiency
}

\author{
Uta Neumann $^{1}$ (D) | Martin J. Whitaker ${ }^{2}$ | Susanna Wiegand ${ }^{1}$ | Heiko Krude ${ }^{1}$ | \\ John Porter ${ }^{2}$ | Madhu Davies² ${ }^{2}$ Dena Digweed ${ }^{2}$ | Bernard Voet ${ }^{2}$ | Richard J. Ross ${ }^{3}$ | \\ Oliver Blankenstein ${ }^{1}$
}

${ }^{1}$ Charité Universitätsmedizin Berlin, Berlin, Germany

${ }^{2}$ Diurnal Limited, Cardiff, UK

${ }^{3}$ The University of Sheffield, Sheffield, UK

\section{Correspondence}

Oliver Blankenstein, Institute for experimental paediatric endocrinology, Charité Universitätsmedizin Berlin, Berlin, Germany. Email: oliver.blankenstein@charite.de

Funding information

This work was funded by the European Commission, Project No, 281654 (FP7 HEALTH) and Diurnal Ltd supported by Glatt GmbH, Germany, and Simbec Research Ltd, United Kingdom.

\section{Summary}

Objectives: There is no licensed, dose-appropriate formulation of hydrocortisone for children with adrenal insufficiency $(\mathrm{Al})$ and patients rely on compounded adult medication. The aim of this study was to evaluate the absorption, palatability and safety of Infacort ${ }^{\circledR}$, an immediate-release, granule formulation of hydrocortisone with taste masking.

Study design: Single site with satellites attended by a "flying" doctor from investigator site. Open-label, single-dose study in three consecutive child cohorts ( $n=24)$ with $\mathrm{Al}$; Cohort 1 , children aged 2 to $<6$ years $(n=12)$; Cohort 2 , infants aged 28 days to $<2$ years $(n=6)$; Cohort 3 , neonates aged 1 to $<28$ days $(n=6)$.

Methods: Fasted children were given a single dose of Infacort ${ }^{\circledR}$ as dry granules administered directly from a capsule or spoon followed by a drink. The primary end-point was the maximum serum cortisol concentration up to 240 minutes after Infacort $^{\circledR}$ administration. Secondary end-points were palatability and adverse events (AEs).

Results: All children showed an increase in cortisol above baseline after Infacort ${ }^{\circledR}$ $(P<.0001)$, with geometric mean \pm SD cortisol concentration at 60 minutes of $575.8 \pm 299.5 \mathrm{nmol} \mathrm{L}^{-1}$. There was no failure in administration of Infacort ${ }^{\circledR}$, and $95.5 \%$ of parents/carers preferred Infacort ${ }^{\circledR}$ to their child's current medication. In 7 children who completed the palatability questionnaire, $80 \%$ of responses were very good or neutral, and $20 \%$ were adverse. No serious or severe treatment-emergent AEs were reported. Conclusions: Infacort ${ }^{\circledR}$ is well tolerated, easy to administer to neonates, infants and children and shows good absorption, with cortisol levels at 60 minutes after administration similar to physiological cortisol levels in healthy children.

KEYWORDS

adrenal insufficiency, congenital adrenal hyperplasia, infants, neonates, oral hydrocortisone granules

This is an open access article under the terms of the Creative Commons Attribution-NonCommercial-NoDerivs License, which permits use and distribution in any medium, provided the original work is properly cited, the use is non-commercial and no modifications or adaptations are made.

(c) 2017 The Authors. Clinical Endocrinology Published by John Wiley \& Sons Ltd 


\section{1 | INTRODUCTION}

The commonest cause of adrenal insufficiency (AI) in childhood is congenital adrenal hyperplasia (CAH), and children require glucocorticoid replacement from birth to end of life. ${ }^{1}$ The recommended replacement therapy is hydrocortisone, ${ }^{2,3}$ but there are no licensed doseappropriate formulations of hydrocortisone for children. Children rely either on parents crushing tablets or pharmacists compounding adult medication. However, compounding is regulated by less stringent criteria than those used for licensed drugs as compounded drugs are neither approved by the European Medicines Agency (EMA) nor Food and Drug Administration (FDA) nor required to demonstrate efficacy. ${ }^{4}$ There is also exemption from Good Manufacturing Practice (GMP) requirement in manufacture for compounded medicines which increases the risks of inaccurate dosing. ${ }^{4} \mathrm{~A}$ recent assessment of 56 batches of hydrocortisone capsules prepared for children in Germany revealed that $25 \%$ did not meet the European Pharmacopoeia acceptance criteria for precision of mass and/or content, ${ }^{5}$ and difficulties with crushing hydrocortisone tablets have been highlighted in the UK. ${ }^{6}$ Furthermore, because hydrocortisone is bitter, powders and suspensions created by compounding pharmacists are often sweetened with sugar to improve palatability (http://www.sickkids.ca/Pharmacy/ Compounding-Service/), which is contrary to current paediatric guidance (Guideline on pharmaceutical development of medicines for paediatric use (1 August 2013 EMA/CHMP/QWP/805880/2012 Rev. 2, Committee for Medicinal Products for Human Use [CHMP], Paediatric Committee [PDCO]).

Hydrocortisone as replacement therapy in Al has a narrow therapeutic index, and patients with $\mathrm{CAH}$ have poor health outcomes in adulthood, which are in part related to treatment in childhood. ${ }^{7,8} \mathrm{~A}$ recent survey of paediatric endocrinologists across 16 countries revealed wide heterogeneity in the hydrocortisone formulations used to treat children, with $60 \%$ using divided licensed tablets. ${ }^{9}$ The lowest dose available for hydrocortisone in the USA is a $5 \mathrm{mg}$ tablet and, in Europe, $10 \mathrm{mg}$, but the average dose used in paediatrics is $2 \mathrm{mg}$ with doses as low as $0.5 \mathrm{mg}$ required for neonates and infants. ${ }^{9}$ A hydrocortisone suspension was available in the USA but is no longer marketed as it was not bioequivalent to tablets. ${ }^{10}$ There is therefore an unmet need to develop a licensed paediatric formulation of hydrocortisone specifically designed for the treatment of children with $\mathrm{Al}$ and $\mathrm{CAH}$.

Paediatric patients have specific requirements for drug formulation that include an appropriate dosing route, improved palatability, ease of administration for caregivers, dosing flexibility and stability. Infacort ${ }^{\circledR}$ (Diurnal Ltd, Cardiff, UK) is a new, immediate-release, multiparticulate granule formulation of hydrocortisone with taste-masking designed to be administered either as dry granules or mixed with a small amount of food, directly into the mouths of neonates, infants and children followed by a drink (Figure 1). Infacort ${ }^{\circledR}$ granules are less than $2 \mathrm{~mm}$ in diameter allowing for dosing safely in neonates (Guidance for Industry Size of Beads in Drug Products Labelled for Sprinkle FDA May 2012). A Phase 1 study of Infacort ${ }^{\circledR}$ demonstrated good tolerability and palatability and bioequivalence to licensed hydrocortisone tablets in healthy volunteers. ${ }^{9}$ Undertaking clinical trials in neonates, infants and children is challenging for practical and ethical reasons and for this reason off-label use accounts for up to $60 \%$ of medicines administered to children in Europe and the United States. ${ }^{11,12}$ To date, there have only been two medications licensed in Europe through the EMA Paediatric Use Marketing Authorisation (PUMA) route. To support a PUMA, and as part of a larger European Commission funded project to improve therapy for children with adrenal insufficiency (http://www.tain-project.org/), we undertook a study in neonates, infants and children aged $<6$ years with $\mathrm{Al}$, designed to evaluate the absorption, palatability and safety of Infacort ${ }^{\circledR}$.

\section{2 | SUBJECTS AND METHODS}

\section{1 | Trial design}

This was a Phase 3, open-label, single-dose study conducted at a single centre; Charité-Universitätsmedizin, Berlin, Germany. The study

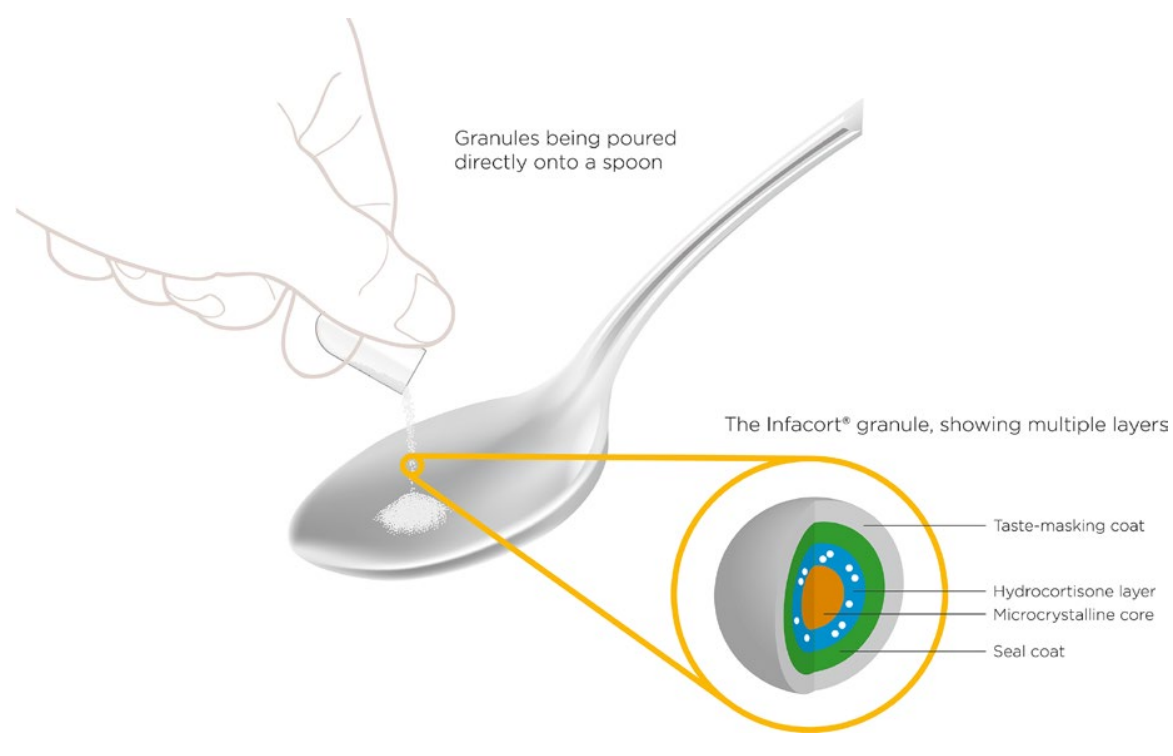

FIGURE 1 Illustration of Infacort ${ }^{\circledR}$ formulation and its administration 
enrolled subjects into three consecutive cohorts: Cohort 1, children (aged 2 to $<6$ years, $n=12$ ); Cohort 2, infants (aged 28 days to $<2$ years, $\mathrm{n}=6$ ); and Cohort 3 , neonates (aged 1 to $<28$ days, $\mathrm{n}=6$ ). Neonatal participants were also recruited at remote sites but had their care transferred to the central site for the duration of the study through a "flying" doctor concept whereby central-site staff visited remote sites to perform study assessments. All participants required hydrocortisone replacement therapy for Al due to CAH or hypopituitarism. Cohorts were studied sequentially such that when no safety issues were found in Cohort 1 then Cohort 2 was recruited. Data were reviewed by the Independent Data Monitoring Committee and BfArM (The Federal Institute for Drugs and Medical Devices) before neonates were enrolled (Cohort 3). The trial comprised three hospital visits: eligibility screening (Visit 1, between Day -28 and -1), dosing (Visit 2, Day 1) and a follow-up visit (Visit 3, on Day 2, 3 or 4)-and a follow-up phone call (Visit 4, between Day 8 and 11).

\subsection{Ethics}

Parents/carers signed an Informed Consent Form. The trial protocol complied with the ethical principles of the Declaration of Helsinki, International Council for Harmonisation (ICH) and Good Clinical Practice (GCP), met with German regulatory authority (BfArM) requirements and was approved by the relevant independent ethics committee (Ethics committee of Berlin, No. 14/0517-EK 12).

Clinical trial registration number: EudraCT No. 2014-002265-30; ClinicalTrials.gov NCT02720952.

\section{3 | Study population}

Comprised adequately hydrated and nourished children (male or female) aged $<6$ years diagnosed with Al (confirmed by an inappropriately low cortisol level) who were currently receiving hydrocortisone with or without fludrocortisone. Children were excluded from the study if they: were experiencing a current adrenal crisis; had clinical signs of acute infection or fever on Day 1; were unable to take oral medications; were receiving concomitant therapy (other than for Al, vitamin D, fluoride, thyroxine and growth hormone, which were permitted); had a parent/carer who could not understand or give written consent or were unwilling to consent to the saving and propagation of pseudonymized medical data in this study (Table 1).

\subsection{Treatment}

Infacort ${ }^{\circledR}$ was supplied as capsules containing 0.5, 1.0, $2.0 \& 5.0 \mathrm{mg}$ doses of immediate-release multiparticulate granules (Figure 1). All participants were given a single dose of Infacort ${ }^{\circledR}$ at study Visit 2 that was equivalent to their routine hydrocortisone dose (Cohort 1: $4.01 \pm 0.8 \mathrm{mg} / \mathrm{m}^{2}$ body surface area (BSA), Cohort 2: $4.98 \pm 0.8 \mathrm{mg} / \mathrm{m}^{2}$ BSA, Cohort 3: $8.43 \pm 2.4 \mathrm{mg} / \mathrm{m}^{2} \mathrm{BSA}$; for further information on dosing see Table $\mathrm{S} 1$ ); the dose was poured directly onto the subject's tongue or on a spoon and administered as dry granules followed by a drink of water or breastmilk in newborns. As food has been noted to delay hydrocortisone absorption and prolong response, ${ }^{13}$ dosing took place at least 2 hours after food in children aged $\geq 1$ year and 45 minutes in children aged $<1$ year and at least 8 hours after their last dose of hydrocortisone. Participants did not eat after Infacort ${ }^{\circledR}$ administration for 60 minutes in children aged $\geq 1$ year and 30 minutes in children aged $<1$ year. Other than replacing their standard morning hydrocortisone dose with Infacort ${ }^{\circledR}$ on the day of administration, subjects continued to receive their standard Al treatment, including fludrocortisone. Subjects continued their standard hydrocortisone treatment 8 hours after Infacort ${ }^{\circledR}$ administration.

\section{5 | End-points}

The primary end-point of this study was maximum serum cortisol concentration up to 240 minutes after Infacort $^{\circledR}$ administration using samples taken at 0, 60 and 240 minutes postdose. Secondary end-points included palatability of Infacort ${ }^{\circledR}, A E s$ and vital signs recorded during the study. Clinical or laboratory events related to a lack of absorption of hydrocortisone from Infacort ${ }^{\circledR}$ were considered as demonstrating a lack of efficacy and were therefore not recorded as AEs.

\subsection{Assessments}

During Visit 2, all study cohorts had blood samples taken at baseline, 60 and 240 minutes for serum cortisol after Infacort ${ }^{\circledR}$ administration. The 60-minute cortisol sample was divided into aliquots with one sample measured immediately for safety using the local immunoassay method (Elecsys Cortisol, Roche Diagnostics). In the protocol, it was stated that if the Investigator judged the participant needed supplementary hydrocortisone after Infacort ${ }^{\circledR}$ administration and/or the 60-minute safety cortisol assessment result was $<100 \mathrm{nmol} \mathrm{L}^{-1}$, an additional cortisol sample would be taken, and emergency hydrocortisone would be administered; however, this action was not taken during the trial. Serum cortisol levels were measured using previously reported, validated, liquid chromatography-mass spectrometry at the central laboratory (Simbec Research Ltd, Merthyr Tydfil, UK) ${ }^{9}$; only baseline and the 60-minute safety cortisol samples were additionally measured at local hospital laboratories. AEs were assessed at Visits 2, 3 and 4 using nondirect questioning following instruction to the parent/carer to observe the child carefully after Infacort ${ }^{\circledR}$ administration. Physical examinations and vital sign assessments (blood pressure, pulse and body temperature) were performed at Visits 1, 2 and 3. In the absence of a validated palatability questionnaire, the study sponsor (Diurnal Ltd, Cardiff, UK) developed a questionnaire in collaboration with the CAH UK Support Group (Leeds, UK). Parents/carers were queried about the palatability of Infacort ${ }^{\circledR}$, after administration, using a 5-item Likert scale and children in Cohort 1 who were able to understand the questions were queried about the palatability of Infacort ${ }^{\circledR}$ after administration using an adjusted 5-item Likert questionnaire (see Table S1). 
TAB LE 1 Demographic and other baseline characteristics. Cohort 1: children aged 2 to < 6 years, Cohort 2: children aged 28 days to $<2$ years. Cohort 3: neonates aged 1 to $<28$ days

\begin{tabular}{|c|c|c|c|c|}
\hline Characteristic & Cohort $1(n=12)$ & Cohort $2(n=6)$ & Cohort $3(n=6)$ & Overall $(n=24)$ \\
\hline Median (range) age, weeks & $171.0(106.3,244.0)$ & $70.9(17.7,94.9)$ & $3.3(2.3,3.7)$ & $100.6(2.3,244)$ \\
\hline \multicolumn{5}{|l|}{ Ethnic origin } \\
\hline White, n (\%) & $12(100)$ & $6(100)$ & $6(100)$ & $24(100)$ \\
\hline Median (ranges) body mass index $\left(\mathrm{kg} / \mathrm{m}^{2}\right)$ & $17.4(14.6,20.6)$ & $17.3(16.4,20.5)$ & $12.3(11.0,15.1)$ & $16.6(11.0,20.6)$ \\
\hline Mean body mass index SDS (SD) & $1.02(1.0)$ & $0.71(0.9)$ & a & \\
\hline Median (ranges) body mass index SDS & $0.96(-0.7,2.1)$ & $-0.31(-1.3,2.0)$ & a & $0.06(-1.3,2.1)$ \\
\hline Mean (SD) body surface area $\left(\mathrm{m}^{2}\right)$ & $0.64(0.08)$ & $0.44(0.08)$ & $0.22(0.03)$ & $0.49(0.19)$ \\
\hline Median (ranges) body surface area $\left(\mathrm{m}^{2}\right)$ & $0.64(0.5,0.8)$ & $0.49(0.3,0.5)$ & $0.22(0.2,0.3)$ & $0.51(0.2,0.8)$ \\
\hline Vitamins & 0 & $1(16.7)$ & $4(66.7)$ & $5(20.8)$ \\
\hline Fludrocortisone & $12(100)$ & $5(83.3)$ & $6(100)$ & $23(95.8)$ \\
\hline Thyroxine & 0 & $1(16.7)$ & 0 & $1(4.2)$ \\
\hline \multicolumn{5}{|l|}{ Concurrent conditions } \\
\hline \multicolumn{5}{|l|}{$n(\%)$} \\
\hline Virilism $^{b}$ & $1(8.3)$ & 0 & $4(66.7)$ & $5(20.8)$ \\
\hline Hypothyroidism & 0 & $1(16.7)$ & 0 & $1(4.2)$ \\
\hline Rhinitis & 0 & $1(16.7)$ & 0 & $1(4.2)$ \\
\hline Skin infection & $1(8.3)$ & 0 & 0 & $1(4.2)$ \\
\hline
\end{tabular}

${ }^{\mathrm{a} B M I-S D S}$ not calculable due to missing reference data in newborns.

${ }^{b}$ Virilisation of the female genitalia according Prader stage II-IV.

\subsection{Statistical methods}

Pharmacokinetic (PK) data from two Phase 1 studies (ClinicalTrials. gov Reference No. NCT02777268 \& NCT01960530) of Infacort ${ }^{\circledR}$ in healthy adult volunteers ${ }^{9}$ were used to derive and minimize the population size in the current study and, as a result, this study aimed to enrol 24 subjects as this provided $>90 \%$ power (alpha 1\%) to demonstrate that cortisol levels were higher than baseline after administration of Infacort ${ }^{\circledR}$. The safety population comprised all subjects who received one complete or partial dose of Infacort ${ }^{\circledR}$. The PK population included all subjects in the safety population for whom there was an adequate set of data to derive the maximum serum concentration $\left(\mathrm{C}_{\max }\right)$ of cortisol without any major PK-related protocol violations (eg incomplete Infacort ${ }^{\circledR}$ intake or vomiting). All cortisol absorption analyses (primary and secondary) were performed based on the PK population, using data determined by the central laboratory. Safety analyses were conducted in the safety population; no formal statistical testing was performed for safety end-points. All variables were presented by cohort and overall. The hypothesis that cortisol $C_{\max }$ up to 240 minutes after Infacort ${ }^{\circledR}$ administration was higher than at baseline was tested using a sign test with a significance level of $1 \%$. This statistical analysis was repeated based on cortisol levels at 60 and 240 minutes after Infacort ${ }^{\circledR}$ administration. A 95\% confidence interval (Cl) for the ratio of maximum cortisol levels versus baseline cortisol levels was presented using a paired $t$ test for log concentration data. Confidence limits based on the log data were back-transformed to provide a $\mathrm{Cl}$ for the ratio. The same approach was used to calculate $95 \% \mathrm{Cls}$ for the ratio of cortisol levels at 60 and 240 minutes after Infacort ${ }^{\circledR}$ administration vs baseline. Cortisol levels were also categorized using the following groups: $<50 \mathrm{nmol} \mathrm{L}^{-1} ; \geq 50$ and $<100 \mathrm{nmol} \mathrm{L}^{-1}$; $\geq 100$ and $<150 \mathrm{nmol} \mathrm{L}^{-1}$; and $\geq 150 \mathrm{nmol} \mathrm{L}^{-1}$. No adjustments for covariates were performed in this study.

\section{3 | RESULTS}

\section{1 | Study population characteristics}

Demographic and other baseline characteristics for the study subjects are shown in Table 1. In total, 24 children were enrolled in the study: Cohort 1, 12 children with CAH, 5 girls and 7 boys; Cohort 2, 5 infants 
with CAH, 1 child with hypopituitarism, 2 girls, 4 boys; Cohort 3, 6 neonates with $\mathrm{CAH}, 4$ girls, 2 boys. One neonate was from the Charité site, and 5 were from satellite sites treated by a "flying" investigator team. Median participant age was 3 years and 3 months and $54.2 \%$ were male; all subjects were white. All subjects were successfully dosed.

\section{2 | Hydrocortisone absorption}

The primary end-point of the study was met as shown in Figure 2. Increases from baseline in cortisol $C_{\max }$ up to 240 minutes after Infacort ${ }^{\circledR}$ administration were statistically significant for the combined study cohorts $(P<.0001)$. A relevant increase from baseline in cortisol $C_{\max }$ was observed in all patients from all three cohorts. The cortisol $C_{\max }$ was observed at 60 minutes in each cohort and overall. The absolute geometric $\pm \mathrm{SD}$ (standard deviation) mean cortisol concentration at $C_{\max }$ was $575.8 \pm 299.5 \mathrm{nmol} \mathrm{L}^{-1}$ for the overall population (Cohort 1: $547.1 \pm 82.9 \mathrm{nmol} \mathrm{L}^{-1}$; Cohort 2: $450.1 \pm 88.9 \mathrm{nmol} \mathrm{L}^{-1}$; Cohort 3: $815.7 \pm 474.9 \mathrm{nmol} \mathrm{L}^{-1}$ ). A summary of the primary efficacy analysis across all study cohorts and the geometric mean serum cortisol concentrations at baseline and after Infacort ${ }^{\circledR}$ administration is shown in Table 2. Results of the primary analysis were confirmed in a secondary analysis using the paired $t$ test. The ratios of geometric means for the comparison of cortisol concentration at $C_{\max }$ (60 minutes)/baseline were statistically significant overall (2535.0 [95\% Cl 1792.4, 3585.3];
$P<.0001)$ and for each cohort $(P<.0001, P=.0007$ and $P<.0001$ for Cohorts 1,2 and 3 , respectively). The ratios of geometric means for cortisol concentrations at $240 \mathrm{~min} /$ baseline were also significant overall $(247.1$ [95\% Cl 161.6, 377.7]; $P=.0002)$ and in Cohort $1(P<.0001)$ but were not significant for Cohorts 2 and $3(P=.4654$ and $P=.0905$, respectively). At 60 minutes $\left(C_{\max }\right), 100 \%$ of the participants had cortisol concentrations $\geq 150 \mathrm{nmol} \mathrm{L}^{-1}$ ( $91.7 \%$ of subjects had a cortisol concentration $<50 \mathrm{nmol} \mathrm{L}^{-1}$ at baseline). By 240 minutes after Infacort ${ }^{\circledR}$ dosing, $41.7 \%$ of participants had cortisol concentrations $<50 \mathrm{nmol} \mathrm{L}^{-1}$, and $8.7 \%$ of participants had cortisol concentrations $\geq 150 \mathrm{nmol} \mathrm{L}^{-1}$.

\section{3 | Palatability}

Infacort ${ }^{\circledR}$ was positively assessed in terms of palatability. Among parents and carers asked about their child's experience of taking the medication ( $n=23$ ), $82.6 \%$ agreed/strongly agreed that their child found swallowing Infacort ${ }^{\circledR}$ easy; 65.2\% agreed/strongly agreed that their child showed a positive reaction after Infacort ${ }^{\circledR}$ administration; $95.5 \%$ would be happy to give their child Infacort ${ }^{\circledR}$ in the future; and 95.5\% said that they would prefer Infacort ${ }^{\circledR}$ for their child's treatment over their usual hydrocortisone formulation. Seven of the 12 children in Cohort 1 (age range 2.6-4.7 years) responded to an adjusted palatability questionnaire. Responses were again generally positive or neutral (Table 3 ), with $\geq 50 \%$ subjects reporting that the taste, feel in
(A)

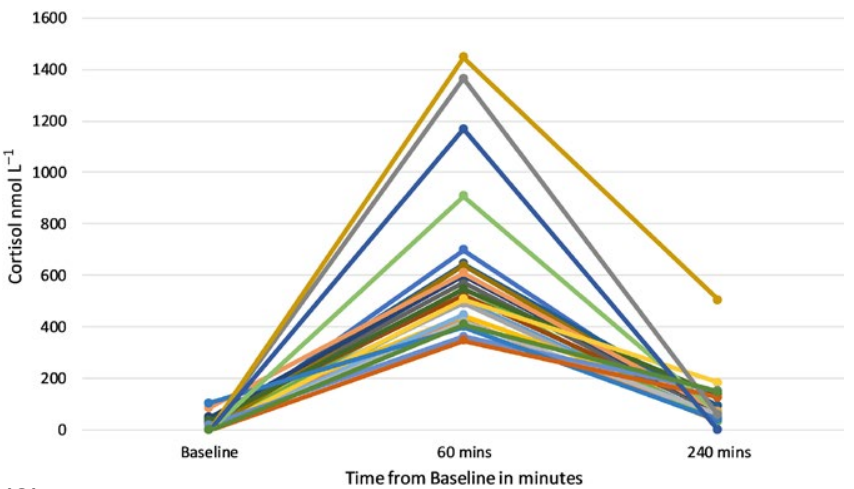

(C)

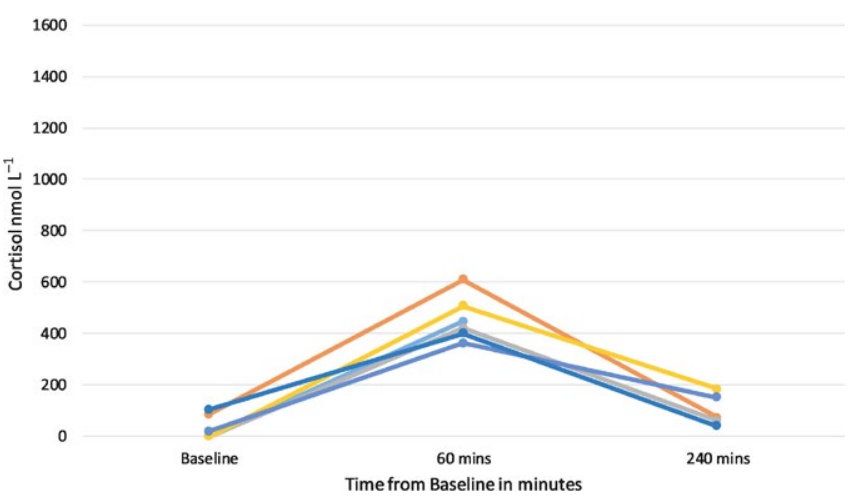

(B)

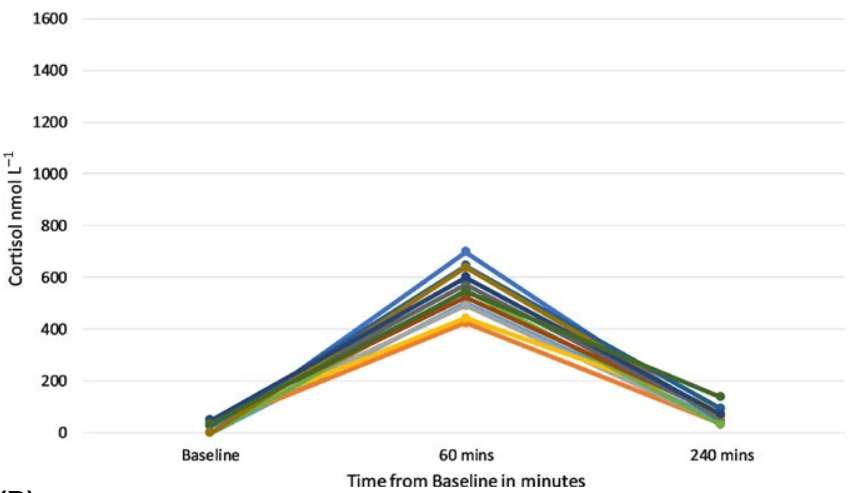

(D)

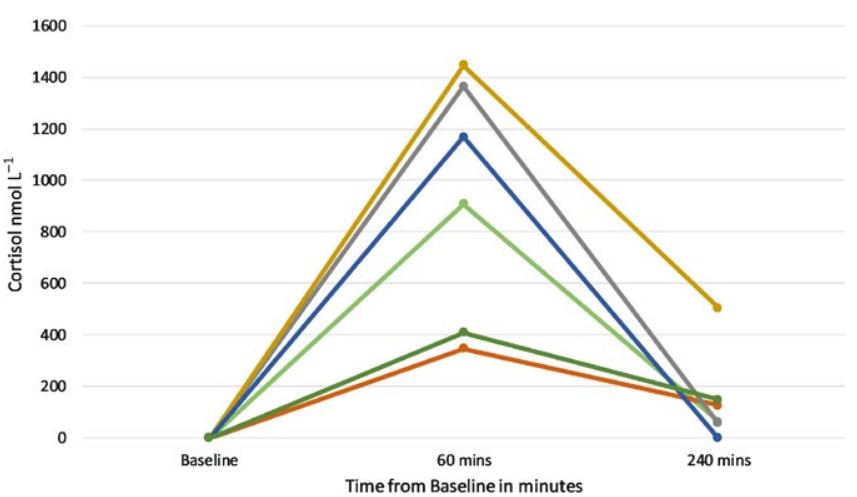

FIGURE 2 Cortisol levels following InfacortR administration in all subjects (A), Cohort 1: children aged 2 to <6 years (B), Cohort 2: infants aged 1 month-<2 years (C) and Cohort 3: neonates aged 1 to $\leq 28$ days (D). InfacortR produced a clinically significant rise in cortisol in all three cohorts 
TABLE 2 Summary of the primary efficacy analysis outcomes

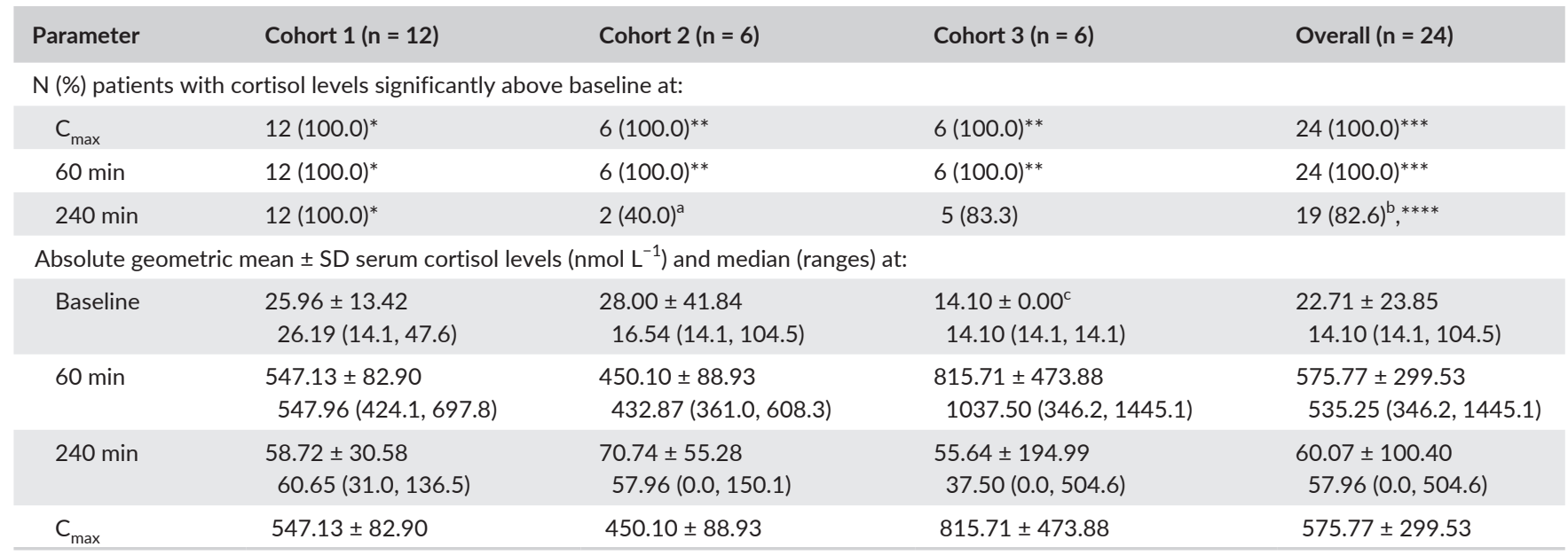

${ }_{n} \mathrm{n}=5$, one subject had no results at 240 minutes.

${ }^{b} \mathrm{n}=23$, one subject had no results at 240 minutes.

${ }^{\mathrm{C} B e l o w ~ l i m i t ~ o f ~ q u a n t i f i c a t i o n ~(B L Q) ~ w a s ~ s e t ~ t o ~ l o w e r ~ l i m i t ~ o f ~ q u a n t i f i c a t i o n ~(L L Q) ~ f o r ~ b a s e l i n e ~ s a m p l e s ~ a n d ~ z e r o ~ f o r ~ p o s t b a s e l i n e ~ s a m p l e s . ~}$

Significance of levels above baseline: ${ }^{*} P=.0005 ;{ }^{* *} P=.0313 ;{ }^{* * *} P<.0001 ;{ }^{* * *} P=.0026$.

TABLE 3 Responses to palatability questionnaire among children in Cohort 1

\begin{tabular}{|c|c|c|c|c|c|c|}
\hline Question & No. of responses & \multicolumn{5}{|c|}{ No. of events (\%) } \\
\hline Q1. How did the medicine smell? & 6 & $1(16.7)$ & 0 & $4(66.7)$ & 0 & $1(16.7)$ \\
\hline Q2. What was it like to swallow the medicine & 6 & $3(50.0)$ & 0 & $1(16.7)$ & 0 & 2 (33.3) \\
\hline Q3. What did the medicine taste like & 6 & $3(50.0)$ & 0 & $3(50.0)$ & 0 & 0 \\
\hline
\end{tabular}

mouth and ease of swallowing were very good and that they were likely to take the medicine again. In addition, 4 of 7 subjects stated that the smell of Infacort ${ }^{\circledR}$ was neutral.

\section{4 | Safety}

There was no significant spillage of granules, and all subjects were successfully dosed (Table 4). Twelve treatment-emergent AEs (TEAEs) were reported by 8 children: $33.3 \%$ of participants overall; $33.3 \%$ of participants in each cohort. No serious or severe TEAEs were reported, and no TEAEs were adjudicated to have resulted from treatment with Infacort ${ }^{\circledR}$. The most common TEAEs reported were diarrhoea, vomiting and rash. No Al events were observed. No changes from baseline in vital signs were reported as TEAEs.

\section{4 | DISCUSSION}

This study examined adrenal replacement therapy in a preschool population using a formulation specifically designed for neonates, infants and children. Infacort ${ }^{\circledR}$ given as dry granules to neonates and children up to 6 years with $\mathrm{Al}$ was well tolerated and provided appropriate exposure to cortisol. The mean cortisol level in the children after taking their standard hydrocortisone dose as Infacort ${ }^{\circledR}$ was $626 \mathrm{nmol} \mathrm{L}^{-1}$, very similar to the mean peak concentrations of cortisol seen in healthy paediatric subjects in the early morning of $691 \mathrm{nmol} \mathrm{L}{ }^{-1} \cdot 14$ All the children had a cortisol concentration at 60 mins $\geq 150 \mathrm{nmol} \mathrm{L}^{-1}$, which is equivalent to the median daily cortisol level in adults ${ }^{15}$ and physiological cortisol levels in adult and paediatric patients are similar. ${ }^{14}$ All of the children who completed the children's questionnaire felt Infacort ${ }^{\circledR}$ tasted good or not bad and parents and carers felt it was better than their child's current medication.

There was no comparator hydrocortisone preparation in this study as there is no licensed dose-appropriate preparation of hydrocortisone, and there is neither a standard method for compounding hydrocortisone nor for administering compounded hydrocortisone. Furthermore, the results of such a study would not be possible to extrapolate to another compounding pharmacy. However, Infacort ${ }^{\circledR}$ given at a dose of $10 \mathrm{mg}$ to adults is bioequivalent to $10 \mathrm{mg}$ hydrocortisone tablets. ${ }^{9}$ The purpose of this study was to demonstrate absorption of Infacort ${ }^{\circledR}$ in young children, and the 60-minute sample time was chosen as this is the approximate time for the $\mathrm{C}_{\max }$ after hydrocortisone in children and adults. ${ }^{9,16}$ There has been no study to date on the pharmacokinetics of hydrocortisone in children under the age of 6 years. However, the 
TAB LE 4 Summary of TEAEs and by system organ class and preferred term

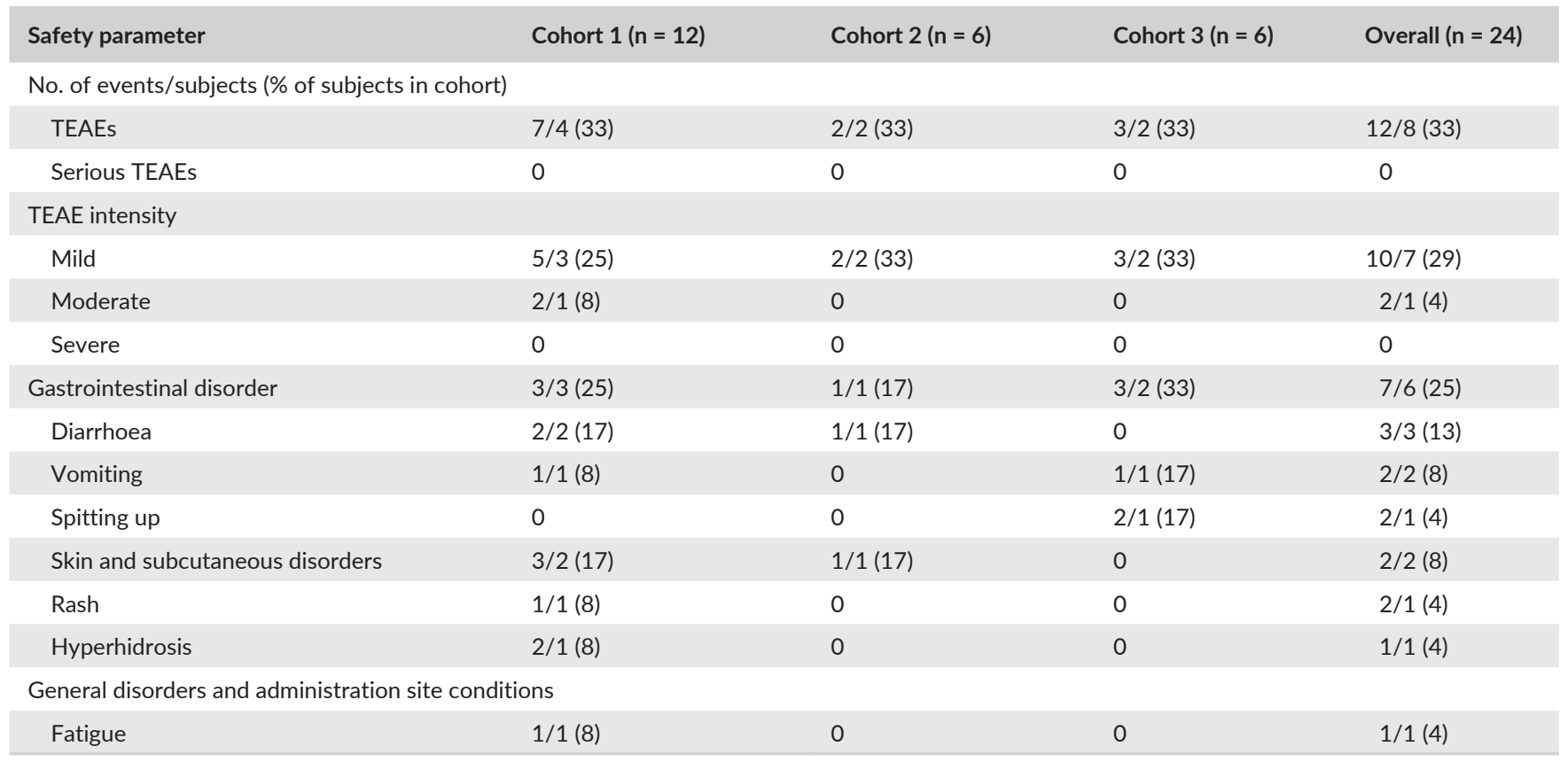

TEAE, treatment-emergent adverse event.

mean $\mathrm{C}_{\max }$ of Infacort ${ }^{\circledR}$ after dosing in these children was $626 \mathrm{nmol} \mathrm{L}^{-1}$, very similar to the reported $C_{\max }$ of a standard $10 \mathrm{mg}$ dose of Infacort ${ }^{\circledR}$ and hydrocortisone tablet given to adults of 566 and $598 \mathrm{nmol} \mathrm{L}^{-1}$, respectively. ${ }^{9}$ Thus, it appears the absorption of Infacort ${ }^{\circledR}$ was similar in very young children to that seen in adults.

By 240 minutes after Infacort, cortisol concentrations for all three cohorts had dropped to $<100 \mathrm{nmol} \mathrm{L}^{-1}$ in the majority of children, although still above baseline in most children. These results are similar to those found in healthy dexamethasone-suppressed volunteers given hydrocortisone $5 \mathrm{mg}$ where the mean \pm SD cortisol was $86 \pm 21 \mathrm{nmol} \mathrm{L}^{-1}$. . These results also reflect the previous reports of cortisol levels during hydrocortisone replacement in paediatrics. ${ }^{17}$ In 20 children on twice or thrice daily hydrocortisone replacement regimens, children on both regimes experienced high peak cortisol concentrations followed by periods of hypocortisolaemia. However, these periods of hypocortisolaemia did not correlate with fatigue or reduced levels of activity. ${ }^{17}$ In children aged 6-20 years studied after their standard morning dose of hydrocortisone, the mean (range) time to a cortisol <100 nmol L ${ }^{-1}$ was 289 (140-540) minutes. ${ }^{16}$ Variability in cortisol levels after oral hydrocortisone administration has been reported and suggested to be due to variability in clearance between patients. ${ }^{16,18}$ The variability in cortisol levels between the cohorts is additionally explained by the higher dose of hydrocortisone per BSA in the neonatal group (cohort 3) who in some centres are dosed with a quarter of a $10 \mathrm{mg}$ tablet as there is no dose-appropriate paediatric formulation. Further studies are now needed to determine the optimum replacement regime in childhood using a therapy such as Infacort ${ }^{\circledR}$ which is available in a dose-appropriate form designed for children.

Drug dosing in neonates is challenging due to significant differences in drug absorption, distribution, metabolism and elimination compared to older children and adults. Most drugs given to neonates are insufficiently studied. ${ }^{19}$ Neonates are extremely vulnerable to medication errors. ${ }^{20}$ Variability in response to oral dosing has been seen in neonates with other oral medications such as phenobarbital, ${ }^{21}$ methadone ${ }^{22}$ and digoxin. ${ }^{23}$

The palatability questionnaire was a parent-reported measure, so may not completely reflect the child's experience. However, parentreported outcome measures have been correlated with clinical outcomes in some childhood illnesses and are standard of care where children are unable to participate. ${ }^{24}$ It was reassuring that in the oldest children who could complete the form, the parents' and children's perceptions of Infacort ${ }^{\circledR}$ seemed similar. Tolerability of Infacort ${ }^{\circledR}$ in children under the age of 6 years was similar to that of adults where the majority considered it either good or neutral. ${ }^{9}$ This is important as compounded hydrocortisone is often mixed with a sweetener, following methods used worldwide, such as Ora-sweet ${ }^{\circledR}$ (Perrigo Company, Allegan, Michigan, USA), which contains sucrose, and so could have led to a nonsweet formulation being poorly received. ${ }^{25,26}$ Sweetening of paediatric formulations in this way, to improve palatability, goes against current recommendations for developing licensed products and raises concerns about accidental ingestion and poisoning in children (Guideline on pharmaceutical development of medicines for paediatric use EMA/CHMP/QWP/805880/2012 Rev. 2). The palatability questionnaire was answered after the first exposure to Infacort $^{\circledR}$ and during the study visit; therefore, it does not reflect continuous daily experience with the drug.

This study highlights the challenges in developing medications for neonates, infants and children and demonstrates that with careful consideration these can be overcome. To address concerns regarding testing in neonates, we used three cohorts of descending age only progressing to test neonates in Cohort 3 after safety had been established in the older cohorts and safety confirmed by an Independent 
Data Monitoring Committee. Recruiting neonates to a clinical trial is a major challenge as recruitment, consent and the study needed to be completed within the first 28 days of life. To address this, we agreed with the ethics committee that there would be a single centre and that the team would travel ("fly") to any site where a neonate with $\mathrm{Al} / \mathrm{CAH}$ was born and administer the trial as from the single site. Germany has a well-established neonatal screening programme with the advantage that clinicians identified neonates shortly after birth. This approach was successful, and 5 of the 6 neonates were recruited from sites outside of the central site.

Limitations in this study include the small number of subjects and the number of samples. However, the investigators and ethics committee were keen that the study should be undertaken as close to routine standard of care as possible, and not include excess samplings. As all children born with $\mathrm{Al}$ are reviewed frequently with blood sampling it was possible to avoid extra visits and extra cannulation. The palatability questionnaire was given to every parent/carer and to every child over 3 years of age. The questionnaire was not completed in 5 of 12 children of the first cohort as they were $<3$ years and/or would not be expected to understand the questionnaire. Assessment of palatability in the very young is challenging but could be undertaken in older children in future studies.

\section{5 | CONCLUSIONS}

The novel, paediatric, multiparticulate granule formulation, Infacort ${ }^{\circledR}$, is well tolerated, easy to administer to neonates, infants and children, and shows good absorption, with cortisol levels at 60 minutes after administration similar to physiological cortisol levels in healthy children. Cortisol levels $>150 \mathrm{nmol} \mathrm{L}^{-1}$ were achieved at $\mathrm{C}_{\max }$ in all subjects, and the mean cortisol level was $580 \mathrm{nmol} \mathrm{L}^{-1}$ for the overall population. Importantly, no safety concerns were reported in this study, and Infacort ${ }^{\circledR}$ was easy to dose and palatable according to both subjects and parents/carers.

\section{ACKNOWLEDGEMENTS}

Editorial support during development of this manuscript was provided by Jane Bryant, PhD and was funded by Diurnal Ltd.

\section{CONFLICT OF INTERESTS}

RJR and MJW are directors and JP and MD employees of Diurnal Ltd. DD and BV are consultants to Diurnal Ltd. The other authors have no conflict of interests relevant to this article to disclose.

\section{AUTHOR CONTRIBUTION}

All authors are responsible for reported research and have participated in the concept and design, analysis and interpretation of data, drafting and revising of the manuscript, and have approved the manuscript as submitted.
ORCID

Uta Neumann (iD http://orcid.org/0000-0003-3892-0577

\section{REFERENCES}

1. Hsieh S, White PC. Presentation of primary adrenal insufficiency in childhood. J Clin Endocrinol Metab. 2011;96:E925-E928.

2. Speiser PW, Azziz R, Baskin LS, et al. Congenital adrenal hyperplasia due to steroid 21-hydroxylase deficiency: an Endocrine Society clinical practice guideline. J Clin Endocrinol Metab. 2010;95:4133-4160.

3. Clayton PE, Miller WL, Oberfield SE, Ritzen EM, Sippell WG, Speiser PW. Consensus statement on 21-hydroxylase deficiency from the European Society for Paediatric Endocrinology and the Lawson Wilkins Pediatric Endocrine Society. Horm Res. 2002;58:188-195.

4. Gudeman J, Jozwiakowski M, Chollet J, Randell M. Potential risks of pharmacy compounding. Drugs R D. 2013;13:1-8.

5. Neumann U, Burau D, Spielmann S, et al. Quality of compounded hydrocortisone capsules used in the treatment of children. Eur J Endocrinol. 2017;177:239-242.

6. Saimbi S, Madden V, Stirling H, Yahyouche A, Batchelor H. Comparison of hydrocortisone $10 \mathrm{mg}$ tablets: tablet hardness optimised for adult use has negative consequences for paediatric use. Arch Dis Child. 2016;101:e2.

7. Han TS, Conway GS, Willis DS, et al. Relationship between final height and health outcomes in adults with congenital adrenal hyperplasia: United congenital adrenal hyperplasia adult study executive (CaHASE). J Clin Endocrinol Metab. 2014;99:E1547-E1555.

8. Finkielstain GP, Kim MS, Sinaii N, et al. Clinical characteristics of a cohort of 244 patients with congenital adrenal hyperplasia. J Clin Endocrinol Metab. 2012;97:4429-4438.

9. Whitaker MJ, Spielmann S, Digweed D, et al. Development and testing in healthy adults of oral hydrocortisone granules with taste masking for the treatment of neonates and infants with adrenal insufficiency. J Clin Endocrinol Metab. 2015;100:1681-1688.

10. Merke DP, Cho D, Calis KA, Keil MF, Chrousos GP. Hydrocortisone suspension and hydrocortisone tablets are not bioequivalent in the treatment of children with congenital adrenal hyperplasia. J Clin Endocrinol Metab. 2001;86:441-445.

11. Czarniak P, Bint L, Favie L, Parsons R, Hughes J, Sunderland B. Clinical setting influences off-label and unlicensed prescribing in a paediatric teaching hospital. PLoS ONE. 2015;10:e0120630.

12. Conroy S, Choonara I, Impicciatore P, et al. Survey of unlicensed and off label drug use in paediatric wards in European countries. European Network for Drug Investigation in Children. BMJ. 2000;320:79-82.

13. Barbhaiya RH, Welling PG. Influence of food on the absorption of hydrocortisone from the gastrointestinal tract. Drug Nutr Interact. 1982;1:103-112

14. Peters CJ, Hill N, Dattani MT, Charmandari E, Matthews DR, Hindmarsh PC. Deconvolution analysis of 24-h serum cortisol profiles informs the amount and distribution of hydrocortisone replacement therapy. Clin Endocrinol (Oxf). 2013;78:347-351.

15. Debono M, Ghobadi C, Rostami-Hodjegan A, et al. Modified-release hydrocortisone to provide circadian cortisol profiles. J Clin Endocrinol Metab. 2009;94:1548-1554

16. Hindmarsh PC, Charmandari E. Variation in absorption and half-life of hydrocortisone influence plasma cortisol concentrations. Clin Endocrinol (Oxf). 2015;82:557-561.

17. Maguire AM, Ambler GR, Moore B, McLean M, Falleti MG, Cowell CT. Prolonged hypocortisolemia in hydrocortisone replacement regimens in adrenocorticotrophic hormone deficiency. Pediatrics. 2007;120:e164-e171

18. Jung C, Greco S, Nguyen $\mathrm{HH}$, et al. Plasma, salivary and urinary cortisol levels following physiological and stress doses of hydrocortisone in normal volunteers. BMC Endocr Disord. 2014;14:91. 
19. Ku LC, Smith PB. Dosing in neonates: special considerations in physiology and trial design. Pediatr Res. 2015;77:2-9.

20. Krzyzaniak N, Bajorek B. Medication safety in neonatal care: a review of medication errors among neonates. Ther Adv Drug Saf. 2016;7:102-119.

21. Pacifici GM. Clinical pharmacology of phenobarbital in neonates: effects, metabolism and pharmacokinetics. Curr Pediatr Rev. 2016;12:48-54.

22. Wiles JR, Isemann B, Mizuno T, et al. Pharmacokinetics of oral methadone in the treatment of neonatal abstinence syndrome: a pilot study. J Pediatr. 2015;167:1214-1220. e1213

23. Yukawa E, Akiyama K, Suematsu F, Yukawa M, Minemoto $M$. Population pharmacokinetic investigation of digoxin in Japanese neonates. J Clin Pharm Ther. 2007;32:381-386.

24. Okelo SO, Eakin MN, Riekert KA, et al. Validation of parental reports of asthma trajectory, burden, and risk by using the pediatric asthma control and communication instrument. J Allergy Clin Immunol Pract. 2014;2:186-192.

25. Jew RK, Soo-Hoo W, Erush SC. Extemporaneous Formulations for Pediatric, Geriatric, and Special Needs Patients. Bethesda: American Society of Health-System Pharmacists; 2010.
26. Orlu-Gul M, Fisco G, Parmar D, Gill H, Tuleu C. A new reconstitutable oral paediatric hydrocortisone solution containing hydroxypropylbeta-cyclodextrin. Drug Dev Ind Pharm. 2013;39:1028-1036.

\section{SUPPORTING INFORMATION}

Additional Supporting Information may be found online in the supporting information tab for this article.

How to cite this article: Neumann U, Whitaker MJ,

Wiegand $\mathrm{S}$, et al. Absorption and tolerability of taste-

masked hydrocortisone granules in neonates, infants and

children under 6 years of age with adrenal insufficiency. Clin

Endocrinol (Oxf). 2017;00:1-9.

https://doi.org/10.1111/cen.13447 